\title{
EFEITO DA ADIÇÃO DE DIFERENTES SUBSTÂNCIAS QUÍMICAS NO EXTRATO DE SEMENTES DE MORINGA UTILIZADO COMO COAGULANTE NO TRATAMENTO DE ESGOTO SANITÁRIO
}

\author{
PAOLA A. V. LO MONACO ${ }^{1}$, ANTONIO T. MATOS ${ }^{2}$, MAGNO DOS S. PEREIRA ${ }^{3}$, \\ VALDEIR EUSTÁQUIO JÚNIOR ${ }^{3}$, ANA PAULA DA S. BATISTA ${ }^{4}$, SANDY A. A. BAKER
}

RESUMO: Este trabalho foi realizado em duas fases. Na primeira, objetivou-se avaliar o efeito de diferentes concentrações de sementes de moringa, aplicadas na forma de extrato, na remoção de turbidez de esgoto sanitário. A segunda fase consistiu em avaliar o efeito da adição de diferentes sais $(\mathrm{NaCl}$ e $\mathrm{KCl})$ e uma base $\left(\mathrm{Ca}(\mathrm{OH})_{2}\right)$ no preparo do extrato de sementes de moringa, com a melhor faixa de remoção obtida na fase 1, utilizada como agente coagulante na remoção de turbidez de esgoto sanitário. De acordo com os resultados obtidos, pôde-se concluir que a máxima eficiência na remoção da turbidez, utilizando-se do extrato de semente de moringa preparado tanto com $\mathrm{NaCl}$ como com $\mathrm{KCl}$, foi obtida na concentração de $2 \mathrm{~g} \mathrm{~L}^{-1}$; das três substâncias químicas utilizadas no experimento, o $\mathrm{Ca}(\mathrm{OH})_{2}$ foi o que demonstrou melhor capacidade de potencializar a ação coagulante das sementes de Moringa oleífera; a adição isolada do extrato de sementes de Moringa oleífera também pode ser considerada eficiente na remoção da turbidez do esgoto doméstico; entretanto, torna-se inviável em razão da grande área necessária para o tratamento de esgoto de uma pequena comunidade.

PALAVRAS-CHAVE: água residuária, coagulantes naturais; efluentes urbanos.

\section{EFFECT OF ADDITION OF DIFFERENT CHEMICAL SUBSTANCES IN MORINGA SEED EXTRACT USED AS COAGULANT IN SEWAGE TREATMENT}

\begin{abstract}
This study was conducted in two phases. The first objective was to evaluate the effect of different concentrations of moringa seed when used in extract form, on turbidity removal of the sewage. The second phase was to assess the effect of addition of different salts $(\mathrm{NaCl}$ e $\mathrm{KCl})$ and a base $\left(\mathrm{Ca}(\mathrm{OH})_{2}\right.$ in the preparation of moringa seed extract, with the best range of removal obtained in phase 1, used as a coagulating agent in removing turbidity from wastewater. According to the results, was concluded that the maximum efficiency in removing turbidity using the moringa seed extract, prepared with both $\mathrm{NaCl}$ and with $\mathrm{KCl}$, was obtained at a concentration of $2 \mathrm{~g} \mathrm{~L}^{-1}$; the three substances used in the experiment, the $\mathrm{Ca}(\mathrm{OH})_{2}$ was demonstrated that the ability to leverage best coagulant action of Moringa oleifera seeds; the addition of the isolated extract of seeds of Moringa oleifera can also be found effective in removing the turbidity of the sewage, however, it is not feasible due to the wide availability of area needed for the treatment of sewage from a small community.
\end{abstract}

KEYWORDS: wastewater, natural coagulants, urban effluents.

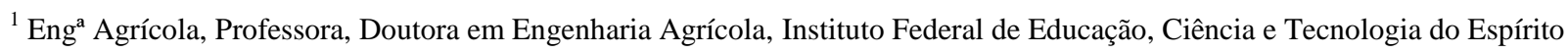
Santo, campus Santa Teresa, paolalm@ifes.edu.br.

${ }^{2}$ Eng. Agrícola, Professor, Doutor em Solos e Nutrição de Plantas, Universidade Federal de Viçosa, Viçosa, MG, atmatos@ufv.br.

${ }^{3}$ Eng. Agrícola e Ambiental, M.s em Engenharia Agrícola, Doutorando em Engenharia Agrícola, Universidade Federal de Viçosa, Viçosa, MG, magno.eaa@gmail.com; vejunior@yahoo.com.br.

${ }^{4}$ Graduando em Engenharia Agrícola e Ambiental, Universidade Federal de Viçosa, Viçosa, MG, anapsbatista@ gmail.com.

${ }^{5}$ Eng. Agrícola e Ambiental, Universidade Federal de Viçosa, Viçosa, MG, sandy_archer_baker@yahoo.com.br.

Recebido pelo Conselho Editorial em: 6-3-2012
}

Aprovado pelo Conselho Editorial em: 6-4-2013 


\section{INTRODUÇÃO}

Coagulantes inorgânicos são normalmente utilizados para remoção de sólidos em suspensão no processo de tratamento da água. Dentre os coagulantes tradicionalmente utilizados, destacam-se o sulfato de alumíno e o sulfato férrico. No entanto, devido à limitada disponibilidade e ao custo relativamente alto, principalmente em pequenas comunidades ou em locais mais afastados, necessita-se encontrar soluções alternativas de tratamento para atenuar problemas associados ao consumo de água não potável e de lançamento de águas residuárias, sem tratamento, em corpos hídricos receptores.

Entre muitas outras propriedades, as sementes de moringa contêm uma proteína coagulante que pode ser usada tanto no tratamento de água para abastecimento como no tratamento de águas residuárias (LO MONACO et al., 2010).

Muitos são os resultados de pesquisas comprovando a eficiência do extrato de sementes de moringa (Moringa oleifera), como agente coagulante, na remoção de diversos poluentes contidos em diferentes tipos de água (ABDULSALAM et al., 2007; BHATIA et al., 2007; HEREDIA \& MARTIN, 2009; MATOS et al., 2007a; LO MONACO et al., 2010; BHUPTAWAT et al., 2007; SILVA et al., 2007; PRITCHARD et al., 2010). Pesquisas têm sugerido, também, que a adição de substâncias químicas no preparo do extrato de moringa pode proporcionar ainda maior eficiência da referida suspensão na coagulação de sólidos em suspensão, em águas residuárias (OKUDA et al., 1999; GHEBREMICHAEL et al., 2005; SÁNCHEZ-MARTÍN et al., 2010).

Nesse sentido, LO MONACO et al. (2012) avaliaram o efeito da adição de $\mathrm{NaCl}$ e de $\mathrm{Ca}(\mathrm{OH})_{2}$ no preparo do extrato de sementes de moringa (Moringa oleifera), quando utilizado na remoção de turbidez da água residuária de suinocultura (ARS). Os autores observaram que, quando foi utilizado extrato de sementes de moringa ou solução de $\mathrm{NaCl} 1 \mathrm{~mol} \mathrm{~L}^{-1}$ ou extrato de sementes de moringa preparadas em solução de $\mathrm{NaCl} 1 \mathrm{~mol} \mathrm{~L}^{-1}$, não houve remoção e, sim, aumento na turbidez da ARS. Esses resultados contrariaram os resultados obtidos por OKUDA et al. (1999) que, ao avaliarem a turbidez residual de água sintética preparada com caulim, utilizando extrato de sementes de moringa preparado em água destilada e extrato de sementes de moringa preparado em solução de $\mathrm{NaCl}$, concluíram que o último proporcionou maior coagulação, em dosagens de massa de sementes 7,4 vezes menores do que as necessárias no preparo de extrato de sementes de moringa com água destilada. Em vista disso, LO MONACO et al. (2012) suspeitaram que a não remoção de turbidez devesse ser creditada à qualidade da água tratada, ou seja, o extrato de sementes de moringa, mesmo quando preparado em solução de $\mathrm{NaCl}$, não é eficaz na remoção da turbidez de águas residuárias ricas em material orgânico, como as de suinocultura. Segundo eles, a baixa remoção da turbidez pode estar relacionada à concentração de ácidos fúlvicos na ARS. CAMPOS et al. (2005), ao estudarem a influência das características das substâncias húmicas na eficiência de coagulação com o sulfato de alumínio, observaram que, quanto maior a porcentagem de ácidos fúlvicos nas frações de substâncias húmicas de diferentes massas molares na água, maior foi a dificuldade na remoção da turbidez da água. Corroborando este fato, LO MONACO et al. (2010), ao avaliarem a eficiência de diferentes concentrações do extrato de sementes de moringa como coagulante, no tratamento de ARS, observaram baixa eficiência do extrato de sementes de moringa, como agente coagulante, quando o material em suspensão é, predominantemente, orgânico. No tratamento de esgoto doméstico, cuja concentração de matéria orgânica é sabidamente menor que a da ARS, obtiveram remoção de $22,4 \%$, ao passo que, no tratamento de água de abastecimento, caracterizada como uma água rica em material inorgânico, mas com baixa concentração de material orgânico, os mesmos autores obtiveram remoção de $98 \%$ da turbidez, numa concentração de $0,4 \mathrm{~g}$ $\mathrm{L}^{-1}$ de sementes de moringa.

LO MONACO et al. (2012) observaram remoção insignificante da turbidez da ARS em tratamento com adição de extrato de sementes de moringa $\left(0,64 \mathrm{~g} \mathrm{~L}^{-1}\right)$ enquanto , quando tratada com suspensão de extrato de sementes de moringa preparado em solução de $\mathrm{Ca}(\mathrm{OH})_{2}\left(0,64 \mathrm{~g} \mathrm{~L}^{-1}\right.$ de cal $+0,64 \mathrm{~g} \mathrm{~L}^{-1}$ de sementes de moringa), foi obtida eficiência de 97,5\%. Considerando que o 
tratamento em que foi adicionado apenas solução de $\mathrm{Ca}(\mathrm{OH})_{2}\left(0,64 \mathrm{~g} \mathrm{~L}^{-1}\right)$ proporcionou eficiência semelhante na remoção de turbidez $(97,4 \%)$, os autores concluíram que a elevada eficiência de remoção nesses dois tratamentos se deveu à presença do $\mathrm{Ca}(\mathrm{OH})_{2}$.

Com base nesses resultados, entende-se que há necessidade de maiores esclarecimentos quanto à atuação da moringa em diferentes tipos de águas residuárias, principalmente aquelas com carga orgânica menor que as águas residuárias de suinocultura, como a de esgoto sanitário, além de doses e formas do preparo de seu extrato. Assim, objetivou-se, com a realização do presente trabalho, avaliar o efeito da adição de diferentes sais e da cal hidratada $\left(\mathrm{Ca}(\mathrm{OH})_{2}\right)$ no preparo do extrato de sementes de moringa, utilizado como agente coagulante, para a remoção de turbidez de esgoto sanitário.

\section{MATERIAIS E MÉTODOS}

A água residuária utilizada nos ensaios foi coletada em reservatório, localizado na Área Experimental de Tratamento de Resíduos Urbanos, do Departamento de Engenharia Agrícola, receptor de esgoto sanitário proveniente do bairro Acamari e adjacências, em Viçosa-MG, apresentando, inicialmente, turbidez média de 61,2 UNT.

$\mathrm{O}$ experimento foi realizado em duas fases. Na primeira, objetivou-se avaliar o efeito de diferentes concentrações de extrato de sementes de moringa, quando utilizado na remoção de turbidez do esgoto sanitário. A segunda fase consistiu em avaliar o efeito da adição de diferentes sais e uma base no preparo do extrato de sementes de moringa, com a melhor faixa de remoção obtida na fase 1, utilizada como agente coagulante na remoção de turbidez de esgoto sanitário.

Para a realização da primeira fase, conduzida nas dependências do Laboratório de Solo e Resíduos Sólidos do Departamento de Engenharia Agrícola, da Universidade Federal de Viçosa (UFV), foram preparados extratos obtidos com a trituração, em liquidificador, de 1; 2; 4 e 5 gramas de sementes de moringa em cada $100 \mathrm{~mL}$ de água destilada (soluções de 10;20; 40 e $50 \mathrm{~g} \mathrm{~L}^{-1}$ ), sendo a suspensão, posteriormente, filtrada em malha de $1 \mathrm{~mm}$. As soluções preparadas eram utilizadas no dia de seu preparo.

Da suspensão de $10 \mathrm{~g} \mathrm{~L}^{-1}$, foram retiradas alíquotas de $1 ; 5 ; 10$ e $20 \mathrm{~mL}$, que foram adicionadas a $500 \mathrm{~mL}$ de esgoto doméstico, de modo a se obter concentrações de 0,02; 0,10;0,20 e 0,40 gramas de sementes por litro de esgoto sanitário. Da suspensão de $20 \mathrm{~g} \mathrm{~L}^{-1}$, retiraram-se alíquotas de 20 e $30 \mathrm{~mL}$, equivalendo às concentrações de 0,8 e 1,2 grama de sementes por litro de esgoto sanitário; da suspensão de $40 \mathrm{~g} \mathrm{~L}^{-1}$ retiraram-se alíquotas de 20 e $30 \mathrm{~mL}$, equivalendo às concentrações de $1,6 \mathrm{e}$ $2,4 \mathrm{~g} \mathrm{~L}^{-1}$, e da suspensão de $50 \mathrm{~g} \mathrm{~L}^{-1}$, retiraram-se alíquotas de 20;30; 40 e $50 \mathrm{~mL}$, equivalendo às concentrações de 2,0; 3,0; 4,0 e 5,0 gramas por litro de esgoto sanitário.

Em seguida, as suspensões foram misturadas nos béqueres em triplicata (três repetições para cada alíquota retirada) e colocadas em agitação no aparelho "Jar-test", permanecendo por 30 segundos sob agitação a $160 \mathrm{rpm}$ e, posteriormente, por 15 minutos, sob agitação a $15 \mathrm{rpm}$. As suspensões foram mantidas por períodos de 2 horas em repouso para a sedimentação do material nos béqueres. Decorrido o período, amostras do sobrenadante foram retiradas dos béqueres para a determinação da turbidez.

Apesar de se saber que os coagulantes apresentam melhor eficiência em determinadas faixas de pH, optou-se por não corrigi-lo na suspensão em tratamento, já que SCHWARZ (2000) e LEDO et al. (2009) constataram que a eficiência do extrato de sementes de moringa independe do pH da água a ser tratada. Os ensaios em "Jar-test" e as análises de turbidez foram realizados no Laboratório de Qualidade da Água do Departamento de Engenharia Agrícola, da Universidade Federal de Viçosa.

Por meio de regressão, foi feito o ajuste de equações matemáticas, relacionando turbidez como função da concentração do extrato de sementes de moringa, tendo sido considerado satisfatório o ajuste que proporcionasse coeficiente de determinação maior que $70 \%$ e apresentasse significância mínima de $10 \%$ de probabilidade nos coeficientes. Para realizar a análise de regressão, utilizou-se o programa Sigma Plot 11.0. 
De posse da faixa de concentração que proporcionou a melhor eficiência na remoção de turbidez do esgoto sanitário, foi conduzida a segunda fase. O experimento consistiu em sete tratamentos: em T1, adicionou-se, ao esgoto sanitário, apenas o extrato de sementes de moringa, preparado com água destilada; em T2, T4 e T6, adicionou-se ao esgoto o extrato de sementes de moringa preparado com diferentes soluções salinas $(\mathrm{NaCl}$ e $\mathrm{KCl})$ e uma base $\left(\mathrm{Ca}(\mathrm{OH})_{2}\right)$; e em $\mathrm{T} 3$, T5 e T7, adicionaram-se ao esgoto apenas as referidas soluções salinas e a base.

O extrato utilizado no T1 foi obtido a partir da trituração de $25 \mathrm{~g}$ de sementes de moringa em 500 $\mathrm{mL}$ de água destilada $\left(50 \mathrm{~g} \mathrm{~L}^{-1}\right)$, no liquidificador, durante 2 minutos. Depois de filtrado em malha de 1 $\mathrm{mm}$, do extrato foram retiradas alíquotas de 20;24;30; 40 e $50 \mathrm{~mL}$, que foram adicionadas a $500 \mathrm{~mL}$ de esgoto doméstico, obtendo-se, respectivamente, as concentrações finais de 2,0; 2,4; 3,0; 4,0 e 5,0 gramas de sementes por litro de esgoto doméstico.

Nos tratamentos T2, T4 e T6, o extrato foi preparado juntando-se $25 \mathrm{~g}$ de sementes de moringa com $500 \mathrm{~mL}$ das soluções preparadas com os sais $\mathrm{NaCl}, \mathrm{KCl}$ e a base $\mathrm{Ca}(\mathrm{OH})_{2}$, colocados individualmente nas concentrações de $1 \mathrm{~mol} \mathrm{~L}^{-1}, 1 \mathrm{~mol} \mathrm{~L}^{-1}$ e $0,011 \mathrm{~mol} \mathrm{~L}^{-1}$, respectivamente. Nos tratamentos T3, T5 e T7, utilizaram-se somente as soluções dos sais $(\mathrm{NaCl}$ e $\mathrm{KCl})$ e o $\mathrm{Ca}(\mathrm{OH})_{2}$, respectivamente, colocados individualmente nas referidas concentrações. Tal como realizado no tratamento T1, a mistura foi, posteriormente, filtrada em malha de $1 \mathrm{~mm}$, obtendo-se uma suspensão final com concentração de $50 \mathrm{~g} \mathrm{~L}^{-1}$ de sementes de moringa e nas concentrações mencionadas de cada sal, nos tratamentos em que foi feita sua adição. Todas as suspensões e soluções foram adicionadas ao esgoto sanitário logo após seu preparo, tal como na primeira fase.

De cada suspensão/solução preparada, foram retiradas alíquotas de 20;24;30; 40 e $50 \mathrm{~mL}$ que foram adicionadas a $500 \mathrm{~mL}$ de esgoto sanitário, o que correspondeu às mesmas concentrações finais utilizadas no tratamento T1 e de 0,$04 ; 0,048 ; 0,06 ; 0,08$ e $0,1 \mathrm{~mol} \mathrm{~L}^{-1}$ dos sais $\mathrm{NaCl}$ e $\mathrm{KCl}$ e $4,4 \times 10^{-4} ; 5,28 \times 10^{-4} ; 6,6 \times 10^{-4} ; 8,8 \times 10^{-4} ; 1,1 \times 10^{-3} \mathrm{~mol} \mathrm{~L}^{-1}$ de $\mathrm{Ca}(\mathrm{OH})_{2}$, quando se utilizaram apenas as soluções salinas e a base. Em seguida, as suspensões/soluções foram misturadas às amostras de esgoto sanitário e colocadas em agitação no aparelho "Jar-test", onde permaneceram por 30 segundos sob agitação a 160 rpm e, posteriormente, por 15 minutos, sob agitação a $15 \mathrm{rpm}$.

De maneira idêntica à primeira fase, as suspensões de esgoto sanitário foram mantidas por períodos de 2 horas em repouso para a sedimentação de partículas nos béqueres. Decorrido esse período de tempo, amostras do sobrenadante foram coletadas nos béqueres para medição da turbidez em turbidímetro, modelo AP 2000.

Em todos os tratamentos, foram realizadas três repetições e, por meio de regressão, foi feito o ajuste de equações matemáticas relacionando a média dos valores de turbidez relativa (UNT/UNT $\left.{ }_{0}\right)$ como função das diferentes concentrações das suspensões/soluções analisadas. Considerou-se satisfatório o ajuste que proporcionasse coeficiente de determinação maior que $70 \%$ e apresentasse significância mínima de 5\% de probabilidade nos coeficientes. Para realizar a análise de regressão, utilizou-se o programa Sigma Plot 11.0.

\section{RESULTADOS E DISCUSSÃO}

$\mathrm{Na}$ Figura 1, está apresentado o gráfico representando os valores médios de turbidez relativa (UNT/UNT ${ }_{0}$ ) nas amostras de esgoto sanitário em função das concentrações de sementes trituradas de moringa e a equação de regressão ajustada, com o respectivo coeficiente de determinação, durante a primeira fase da experimentação. 


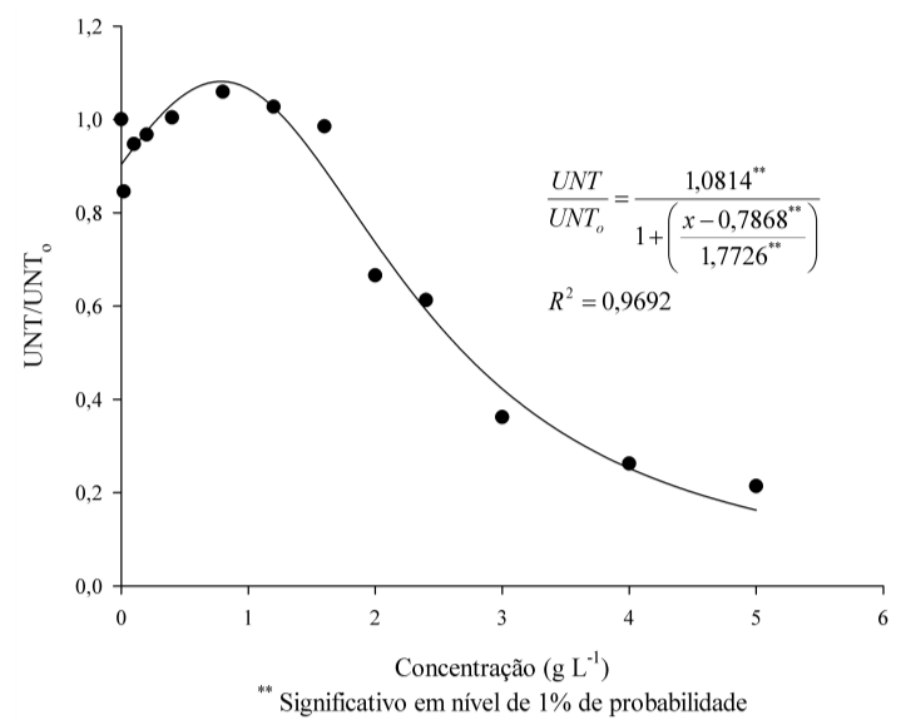

FIGURA 1. Valores médios de turbidez relativa (UNT/UNT0) nas amostras de esgoto sanitário em função das concentrações de sementes trituradas de moringa (SM). Mean values of relative turbidity $\left(\mathrm{UNT} / \mathrm{UNT}_{\mathbf{0}}\right)$ in sewage samples in different concentrations of powdered seeds of moringa (SM).

De acordo com o que está apresentado na Figura 1, pode-se verificar que a turbidez da amostra de esgoto doméstico aumentou até próximo da concentração de $1 \mathrm{~g} \mathrm{~L}^{-1}$ de sementes trituradas de moringa, na forma de extrato. Acredita-se que essa elevação da turbidez esteja associada às baixas concentrações de sementes de moringa no extrato adicionado à amostra de esgoto doméstico, o que não proporcionou suficiente fornecimento da proteína responsável pelo processo de coagulação dos sólidos em suspensão na amostra, tendo sido, no entanto, suficiente para proporcionar aumento na turbidez da água residuária em tratamento, provocada pela adição do próprio material orgânico contido nas sementes de moringa. Estes resultados corroboram os encontrados por LO MONACO et al. (2012), que ao utilizarem concentrações do extrato de sementes de moringa menores que $1 \mathrm{~g}$ por litro de água residuária de suinocultura tratada $(0,04$; 0,08; 0,16; 0,32 e 0,64 $\mathrm{g} \mathrm{L}^{-1}$ ), não observaram remoção da turbidez, creditando este fato, também, ao aumento do material orgânico oriundo da própria semente de moringa.

De acordo com OKUDA et al. (2001) e GHEBREMICHAEL et al. (2005), há a possibilidade de incremento do carbono orgânico dissolvido da água tratada, devido à incorporação de matéria orgânica adicional originária das sementes e que acompanha o agente coagulante efetivo. Ao que tudo indica, a partir da adição de $1,0 \mathrm{~g} \mathrm{~L}^{-1}$ de sementes trituradas, na forma de extrato, à amostra, o efeito coagulante passou a superar o aumento na concentração de material orgânico, decorrente da adição do extrato de sementes trituradas à amostra, proporcionando floculação dos sólidos suspensos e, com isso, diminuição na turbidez do esgoto doméstico.

Para se obter a concentração recomendável de sementes de moringa referente à menor concentração relativa de turbidez (UNT/UNT ${ }_{0}$ ), aplicou-se a regressão linear Response Plateau para a obtenção da equação ajustada e, com isso, estimar a menor concentração de sementes de moringa que proporcionasse máxima remoção de turbidez do esgoto sanitário.

A concentração ótima de sementes de moringa trituradas foi de 4,8 gramas por litro de esgoto doméstico, já que proporcionou o menor valor de concentração relativa de turbidez no esgoto doméstico, obtendo-se uma remoção de $77 \%\left(\mathrm{UNT}_{\mathrm{UNT}}=0,23\right)$. A partir deste valor, até a concentração máxima avaliada $\left(5 \mathrm{~g} \mathrm{~L}^{-1}\right)$, a concentração relativa de turbidez (UNT/UNT $\left.{ }_{0}\right)$ passou a ser constante. A remoção encontrada foi superior à obtida por LO MONACO et al. (2010), que observaram remoção média de $22,3 \%$ na turbidez de esgoto sanitário, avaliando concentrações entre 0,02 e $1,2 \mathrm{~g} \mathrm{~L}^{-1}$. Esses autores obtiveram a maior remoção (28\%) quando utilizaram a concentração de $0,4 \mathrm{~g} \mathrm{~L}^{-1}$. 
Nas Figuras 2, 3 e 4, estão apresentados os valores de turbidez relativa (UNT/UNT 0 ) nas amostras de esgoto sanitário, em função das concentrações de sementes trituradas de moringa a elas adicionadas, nas seguintes formas: extrato preparado em água destilada (T1) e extrato preparado em soluções salinas $(\mathrm{NaCl}$ e $\mathrm{KCl})$ e uma solução básica $\left(\mathrm{Ca}(\mathrm{OH})_{2}\right)$, respectivamente, tratamentos $\mathrm{T} 2$, T4 e T6. Além disso, foram incluídos três tratamentos (T3, T5 e T7), nos quais foram adicionadas às amostras de esgoto as mesmas soluções salinas e básica puras. $\mathrm{Na}$ Tabela 1, estão apresentadas as equações das curvas estimadas em todos os tratamentos e seus respectivos coeficientes de determinação.
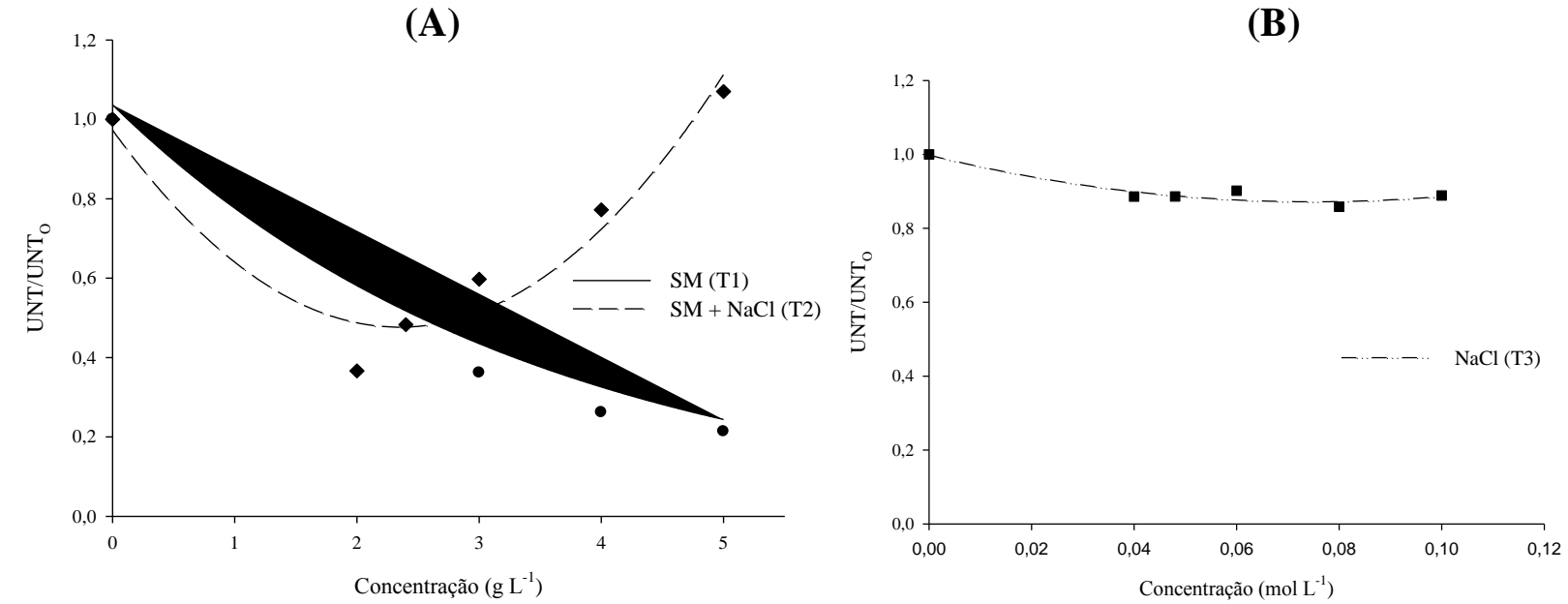

FIGURA 2. (A) Valores de turbidez relativa em função da concentração de sementes de moringa: adição de extrato de sementes de moringa (SM (T1)) e extrato de sementes de moringa $+\mathrm{NaCl}(\mathrm{SM}+\mathrm{NaCl}(\mathrm{T} 2)) ;$ (B) Valores de turbidez relativa em função da concentração de $\mathrm{NaCl}(\mathrm{NaCl}(\mathrm{T} 3))$. (A) Values of turbidity as a function relative concentration of moringa seeds: addition of moringa seed extract (SM (T1)) and moringa seed extract + $\mathrm{NaCl}(\mathrm{SM}+\mathrm{NaCl}(\mathrm{T} 2))$; (B) Values relative turbidity as a function of $\mathrm{NaCl}$ concentration ( $\mathrm{NaCl}(\mathrm{T3}))$.
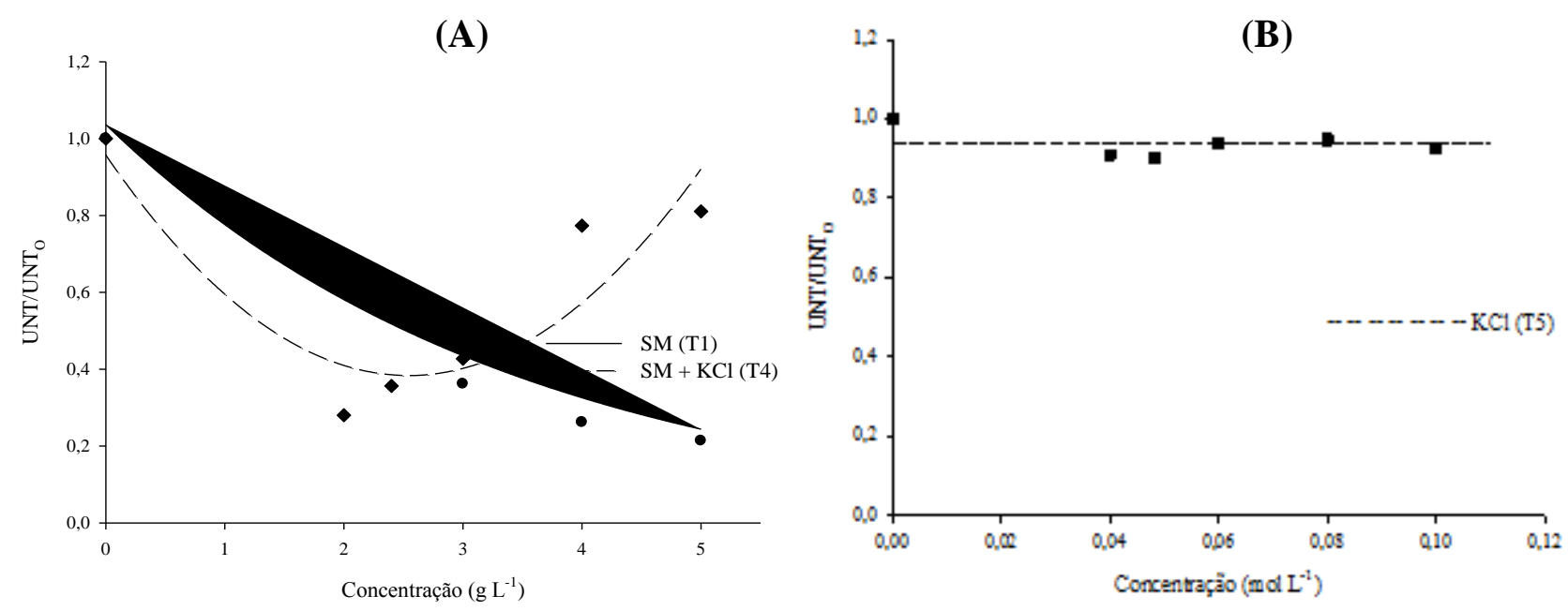

FIGURA 3. (A) Valores de turbidez relativa em função da concentração de sementes de moringa: adição de extrato de sementes de moringa (SM (T1)) e solução de extrato de sementes de moringa $+\mathrm{KCl}(\mathrm{SM}+\mathrm{KCl}(\mathrm{T} 4))$; (B) Valores de turbidez relativa em função da concentração de $\mathrm{KCl}(\mathrm{KCl}$ (T5)). (A) Values of turbidity as a function of relative concentration of moringa seeds:(A) addition of moringa seed extract (SM (T1)) and solution of moringa seed extract $+\mathrm{KCl}(\mathrm{SM}+\mathrm{KCl}(\mathrm{T} 4))$; (B) values relative turbidity as a function of $\mathrm{KCl}$ concentration ( $\mathrm{KCl}(\mathrm{T5}))$. 
(A)

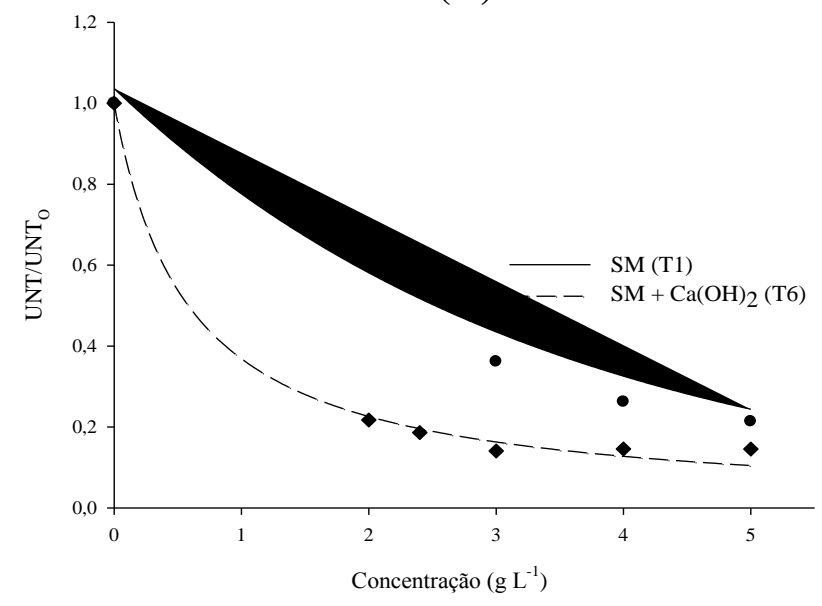

(B)

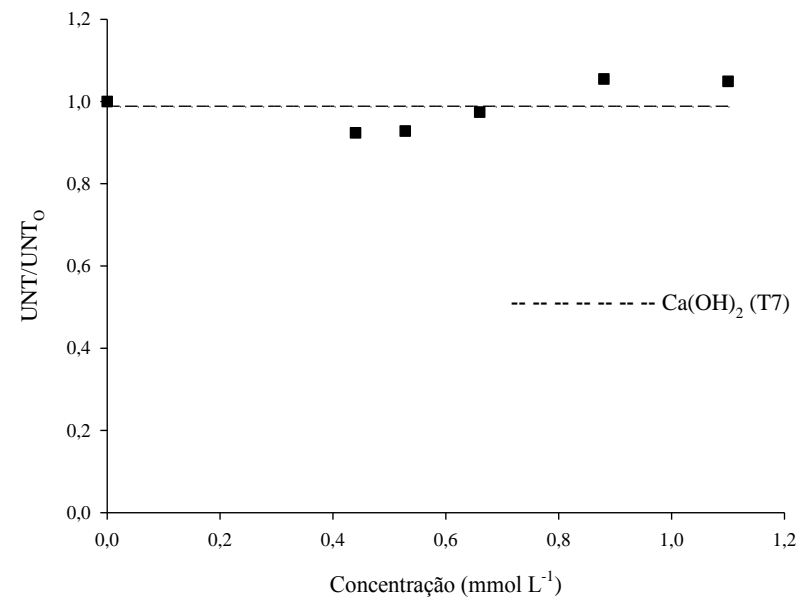

FIGURA 4. (A) Valores de turbidez relativa em função da concentração de sementes de moringa: adição de extrato de sementes de moringa (SM (T1)) e solução de extrato de sementes de moringa $+\mathrm{Ca}(\mathrm{OH})_{2}\left(\mathrm{SM}+\mathrm{Ca}(\mathrm{OH})_{2}(\mathrm{~T} 6)\right)$; (B) Valores de turbidez relativa em função da concentração de $\mathrm{Ca}(\mathrm{OH})_{2}\left(\mathrm{Ca}(\mathrm{OH})_{2}(\mathrm{~T} 7)\right)$.A) Values of turbidity as a function of relative concentration of moringa seeds: addition of moringa seed extract (SM (T1)) and solution of moringa seed extract $+\mathrm{Ca}(\mathrm{OH})_{2}\left(\mathrm{SM}+\mathrm{Ca}(\mathrm{OH})_{2}\right.$ (T6)); (B) values relative turbidity as a function of $\mathrm{Ca}(\mathrm{OH})_{2}$ concentration $\left(\mathrm{Ca}(\mathrm{OH})_{2}(\mathrm{~T} 7)\right)$.

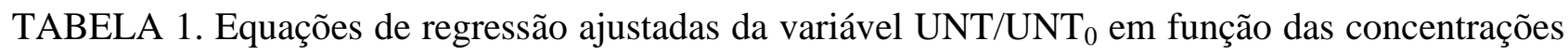
e respectivos coeficientes de determinação para os diferentes tratamentos utilizados. Regression equations adjusted UNT/UNT $\mathbf{U}_{0}$ variable depending on the concentrations and their coefficients of determination for the different treatments.

\begin{tabular}{ccc}
\hline Tratamento & Equação & $\boldsymbol{R}^{2}$ \\
\hline $1(\mathrm{SM})$ & $\hat{y}=1,0366^{* 8} e^{-0,2894^{* *} x}$ & 0,94 \\
$2(\mathrm{SM}+\mathrm{NaCl})$ & $\hat{y}=0,9732^{* 8}-0,4236^{* 8} \mathrm{x}+0,0903^{* 8} \chi^{2}$ & 0,93 \\
$3(\mathrm{NaCl})$ & $\hat{y}=0,9981^{* 8}-3,3746^{*} \mathrm{x}+22,5597^{*} x^{2}$ & 0,92 \\
$4(\mathrm{SM}+\mathrm{KCl})$ & $\hat{y}=0,9578^{* 8}-0,4520^{*} \mathrm{x}+0,0889^{*} x^{2}$ & 0,83 \\
$5(\mathrm{KCl})$ & $\hat{y}=0,9369$ & - \\
$6\left(\mathrm{SM}+\mathrm{Ca}(\mathrm{OH})_{2}\right)$ & $\hat{y}=\frac{1}{\left(1+1,7156^{* 8} x\right)}$ & 0,99 \\
$7\left(\mathrm{Ca}(\mathrm{OH})_{2}\right)$ & $\hat{y}=0,9883$ & - \\
\hline
\end{tabular}

* e ** significativo em nível de 5 e $1 \%$ de probabilidade, respectivamente.

De acordo com os resultados apresentados nas Figuras 2A e 3A, verificou-se que a presença dos sais $(\mathrm{NaCl}$ e $\mathrm{KCl})$ em solução diminuiu o efeito coagulante das sementes de moringa, embora em maiores concentrações salinas, aparentemente isso tenha deixado de ocorrer. De acordo com DUARTE et al. (1998), concentrações salinas compreendidas entre 0,5 e $1 \mathrm{~mol} \mathrm{~L}^{-1}$ (para os sais neutros, tal como os utilizados neste trabalho) podem elevar a solubilidade da proteína (efeito salting in) devido ao aumento em sua solvatação. Essa ação benéfica do sal tem sido utilizada nas indústrias alimentícias, que utilizam o $\mathrm{NaCl}$ como ingrediente alimentar, visando a aumentar a solubilidade e a estabilidade, melhorando, assim, as propriedades emulsificantes de vários produtos. Por outro lado, quando os níveis de sais superam determinados valores, passam a predominar as interações água-sal, em detrimento das interações água-proteína (efeito salting out), contribuindo 
para reduzir a solubilidade proteica. Como, neste trabalho, utilizaram-se concentrações variando de 0,04 a $0,1 \mathrm{~mol} \mathrm{~L}^{-1}$ de $\mathrm{NaCl}$ e $\mathrm{KCl}$, ou seja, abaixo de $0,5 \mathrm{~mol} \mathrm{~L}^{-1}$, o efeito salino não foi suficiente para proporcionar a solubilização das proteínas do extrato de sementes de moringa, o que pode ter dificultado ou impedido sua ação como agente de coagulação. OKUDA et al. (1999), ao avaliarem a turbidez residual de água sintética preparada com caulim, utilizando extrato de sementes de moringa preparado com água destilada e preparado com $\mathrm{NaCl}$, concluíram que o extrato preparado com $\mathrm{NaCl}$ teve melhor desempenho como coagulante, com dosagens de 7,4 vezes menores do que quando o extrato foi preparado com água destilada, na redução da turbidez da água. Os autores utilizaram, no entanto, a concentração de $1 \mathrm{~mol} \mathrm{~L}^{-1}$ e afirmaram que o aumento da força iônica pelo sal causou o aumento na solubilidade dos componentes ativos presentes nas sementes da moringa.

Pelo que pôde ser observado, a adição da solução de extrato de sementes de moringa preparada com $\mathrm{NaCl}$ e com $\mathrm{KCl}$ apresentaram comportamento quadrático e semelhante (Figuras $2 \mathrm{~A}$ e 3A), demonstrando que o preparo do extrato de sementes de moringa com esses dois sais somente foi mais eficiente que o preparado com água destilada, na remoção da turbidez do esgoto sanitário, em concentrações menores que $2,8 \mathrm{~g} \mathrm{~L}^{-1}$, no caso do $\mathrm{NaCl}$, e menores que $3,2 \mathrm{~g} \mathrm{~L}^{-1}$, no caso do $\mathrm{KCl}$, com eficiências de aproximadamente $50 \%$ e $58 \%$, respectivamente. Valores acima dessa concentração proporcionaram aumento na turbidez relativa, indicando que tanto o $\mathrm{NaCl}$ como o $\mathrm{KCl}$ promoveram inibição das propriedades coagulantes das sementes de moringa, sendo o aumento na turbidez decorrente do aumento na adição das partículas de sementes ao esgoto sanitário, tal como observado na primeira fase. A máxima eficiência na remoção da turbidez foi obtida quando foi utilizada uma dose de 2 gramas de sementes $\mathrm{L}^{-1}$ preparada em $\mathrm{NaCl}$ ou $\mathrm{KCl}$, tendo, nessa condição, sido obtidas remoções de 62 e $71 \%$, respectivamente. Comparando estes últimos resultados com o obtido com o extrato preparado com água destilada (Figuras 1, 2A e 3A), observa-se que foi necessária a utilização de 4,86 gramas de sementes por litro de esgoto para se obter uma eficiência de $77 \%$, sugerindo que utilizar o $\mathrm{KCl}$ no preparo do extrato de sementes pode ser mais vantajoso, considerando a pouca diferença na eficiência e a elevada diferença na dose, ou seja, no gasto de sementes de moringa.

Não foi possível apresentar um modelo matemático que descrevesse o comportamento da turbidez relativa em função da concentração $\left(\mathrm{mol} \mathrm{L}^{-1}\right)$, para o tratamento T5. Dessa forma, apresenta-se, na Figura 3B, a média dos valores dessa variável.

A adição única das soluções de $\mathrm{NaCl}$ e $\mathrm{KCl}$ não proporcionou efeitos detectáveis na turbidez das amostras de esgoto sanitário, já que a remoção alcançada ficou em torno de 10\%, independentemente dos valores de concentração avaliados (Figuras 2B e 3B). De maneira semelhante, OKUDA et al. (1999) não observaram qualquer atividade de coagulação quando utilizaram somente a solução de $\mathrm{NaCl} 1 \mathrm{~mol} \mathrm{~L}^{-1}$ em água sintética preparada com caulim.

De acordo com o que está apresentado na Figura 4A, pode-se observar que a adição do extrato de sementes de moringa preparado com $\mathrm{Ca}(\mathrm{OH})_{2}$ proporcionou eficiências de remoção de turbidez de amostras de esgoto sanitário na faixa de 80 a $85 \%$. Para se determinar qual a dose ótima a partir da qual não haveria diferença estatística na $\mathrm{UNT/UNT}$, aplicou-se a regressão linear Response Plateau, cuja equação ajustada estimou-se que a partir da dose $2,2 \mathrm{~g} \mathrm{~L}^{-1}$ não houve diferença estatística na concentração relativa da turbidez.

De todas as substâncias químicas avaliadas, o $\mathrm{Ca}(\mathrm{OH})_{2}$ demonstrou ser o mais eficiente na remoção da turbidez de esgoto sanitário, o que permite inferir que, nas concentrações estudadas, o cálcio tenha potencializado as propriedades coagulantes das sementes de moringa. OKUDA et al. (2001), ao investigarem o mecanismo de coagulação do componente ativo extraído e purificado das sementes de Moringa oleífera com solução salina, no tratamento de água sintética contendo caulim, observaram que a moringa apresentou maior capacidade coagulante quando na presença de cátions bivalentes como o $\mathrm{Ca}^{+2}, \mathrm{Mg}^{+2} \mathrm{e} \mathrm{Ba}^{+2}$ (soluções salinas preparadas de $\mathrm{MgCl}_{2}, \mathrm{CaCl}_{2}$ e $\mathrm{BaCl}_{2}$ ) e baixa capacidade de coagulação quando na presença de sais do tipo $\mathrm{KCl}, \mathrm{NaCl}$ e $\mathrm{NH}_{4} \mathrm{Cl}$. Segundo os autores, quando cátions bivalentes, como o $\mathrm{Ca}^{2+}$, são adsorvidos ao componente ativo da 
coagulação (proteínas), possibilitam a ligação entre suas moléculas, formando matéria insolúvel ("estruturas em rede") capaz de executar uma "varredura", ou seja, captura dos sólidos suspensos por interceptação. Assim, os autores sugerem que o mecanismo de coagulação parece ser o de varredura.

A adição apenas de solução de $\mathrm{Ca}(\mathrm{OH})_{2}$ (Figura 4B) proporcionou, tal como observado em relação aos dois sais, aumento na turbidez relativa com o aumento na concentração, contrariando os resultados encontrados por MATOS et al. (2007b), que ao adicionarem a cal hidratada na dose de 3 $\mathrm{g} \mathrm{L}^{-1}$ à água residuária, quando em recirculação no processamento dos frutos do cafeeiro, observaram considerável remoção de sólidos em suspensão e DQO.

$\mathrm{O}$ preparo do extrato de sementes de moringa com o $\mathrm{Ca}(\mathrm{OH})_{2}$ proporcionou elevada remoção (80 a 85\%) de turbidez, aplicando-se uma dose ótima de $2,2 \mathrm{~g} \mathrm{~L}^{-1}$ de esgoto doméstico, comparado com o extrato preparado com água destilada, que apresentou a eficiência máxima de $77 \%$, aplicando-se uma dose ótima de 4,8 $\mathrm{g} \mathrm{L}^{-1}$. Apesar das elevadas eficiências obtidas, a quantidade de sementes necessária para o tratamento de esgoto de uma pequena comunidade é elevada, podendo vir a ser inviável em locais de terrenos valorizados. Baseando-se nas informações apresentadas por AL AZHARIA JAHN (1986), de que a moringa pode produzir, em média, 17.500 sementes por planta, por ano, e, além disso, considerando que o espaçamento entre plantas seria de $3 \mathrm{~m}$, uma comunidade de 800 habitantes, que gera $100 \mathrm{~L}$ de esgoto habitante ${ }^{-1} \mathrm{~d}^{-1}$, precisaria de 17,5 ha cultivados com plantas de moringa, quando se utilizar a dose de 4,8 gramas de sementes de moringa (preparada com água destilada) por litro de esgoto a ser tratado. Já ao se utilizar a dose de 2,2 gramas de sementes de moringa, utilizando o $\mathrm{Ca}(\mathrm{OH})_{2}$ no preparo de seu extrato, seriam necessários 9 ha cultivados com plantas de moringa, ainda assim, grande área de cultivo. Dessa forma, entendese que haja a necessidade de um tratamento primário, como, por exemplo, a utilização de filtros orgânicos, antes de o esgoto sanitário bruto passar pelo processo de coagulação. Possuindo o efluente do filtro orgânico menor quantidade de sólidos em suspensão, gastar-se-á menor quantidade de sementes no processo. Sustentando essa observação, Borba (2001) estudou a viabilidade da utilização da Moringa oleifera como coagulante natural para clarificação de água com cor e turbidez elevadas, realizando ensaios de coagulação/floculação. Embora o autor tenha obtido ótimos resultados na redução da turbidez, principalmente quando utilizou a polpa da semente, concluiu que o uso da Moringa oleífera, como coagulante natural, bem como auxiliar de coagulação, é inviável para sistemas comunitários, considerando a grande problemática de obtê-la em quantidades suficientes para operar sistemas desse porte.

\section{CONCLUSÃO}

De acordo com os resultados obtidos, pôde-se concluir que:

- A adição de soluções salinas $(\mathrm{NaCl}, \mathrm{KCl})$ e da base $\left.\mathrm{Ca}(\mathrm{OH})_{2}\right)$ ao esgoto sanitário não proporcionou efeitos significativos em sua turbidez.

- A máxima eficiência na remoção da turbidez, utilizando-se do extrato de semente de moringa, preparado tanto com o $\mathrm{NaCl}$ como com o $\mathrm{KCl}$, foi obtida na concentração de $2 \mathrm{~g} \mathrm{~L}^{-1}$, obtendo-se valores de $62 \%$ e $71 \%$, respectivamente.

- A adição da suspensão do extrato de sementes de moringa preparada com os sais $\mathrm{NaCl}$ e $\mathrm{KCl}$,em concentrações maiores que 2,5 e $2,8 \mathrm{~g} \mathrm{~L}^{-1}$ de sementes de moringa, respectivamente, não proporcionou aumento na redução da turbidez, quando os resultados obtidos foram comparados aos ensaios em que foram utilizados apenas extrato de sementes.

- Das três substâncias químicas utilizadas no experimento, o $\mathrm{Ca}(\mathrm{OH})_{2}$ foi o que demonstrou melhor capacidade de potencializar a ação coagulante das sementes Moringa oleifera, tendo sido obtida eficiência de $85 \%$ na remoção de turbidez do esgoto sanitário, quando utilizada a concentração de $2,2 \mathrm{~g} \mathrm{~L}^{-1}$ de sementes.

- A adição isolada do extrato de sementes de Moringa oleífera também pode ser considerada 
eficiente na remoção da turbidez do esgoto sanitário, tendo sido obtido o valor de $77 \%$ quando utilizada a concentração de $4,8 \mathrm{~g} \mathrm{~L}^{-1}$ de sementes de moringa; entretanto, torna-se inviável em razão do grande requerimento de área de cultivo do vegetal para propiciar o tratamento de esgoto de uma pequena comunidade.

\section{AGRADECIMENTOS}

Os autores agradecem ao CNPq, pelo apoio e financiamento deste trabalho.

\section{REFERÊNCIAS}

ABDULSALAM, S.; GITAL, A.A.; MISAU, I.M.; SULEIMAN, M.S. Water clarification using Moring oleifera seed coagulant: Maiduguri raw water as a case study. Journal of Food, Agriculture \& Environment, Helsinki, v.5, n.1, p.302-306, 2007.

AL AZHARIA JAHN S. Proper use of African natural coagulants for rural water supplies: research in the Sudan and guide for new projects. Eschborn: GTZ, 1986. 541p.

BHATIA, S.; OTHMAN, Z.; AHMAD, A.L. Pretreatment of palm oil mill effluent (POME) using Moringa oleifera seeds as natural coagulant. Journal of Hazardous Materials, Amsterdam, v.145, n.1, p.120-126, 2007.

BHUPTAWAT, H.; FOLKARD, G.K.; CHAUDHARI, S. Innovative physico-chemical treatment of wastewater in corporating Moringa oleifera seed coagulant. Journal of Hazardous Materials, Amsterdam, v.142, n.1, p.477-482, 2007.

BORBA, L.R. Viabilidade do uso da Moringa oleífera Lam no tratamento simplificado de água para pequenas comunidades. 2001. 92 f. Dissertação (Mestrado em Desenvolvimento e Meio Ambiente), Universidade Federal da Paraíba, João pessoa, 2001.

CAMPOS, S.X.; BERNARDO, L.D.; VIEIRA, E.M. Influência das características das substâncias húmicas na eficiência da coagulação com sulfato de alumínio. Engenharia Sanitária e Ambiental, Rio de Janeiro, v.10, n.3, p.194-199, jul./set., 2005.

DUARTE, A.J.; CARREIRA, R.L.; JUNQUEIRA, R.G.; COELHO, J.V.; SILVESTRE, M.P.C. Propriedades emulsionantes e solubilidade da caseína bovina: 2. Efeito da adição de NaCl. Ciência e Tecnologia de Alimentos, Campinas, v.18, n.3, p.295-302, 1998.

GHEBREMICHAEL, K.A.; GUNARATNA, K.R.; HENRIKSSON, H.; BRUMER, H.;

DALHAMMAR, G. A simple purification and activity assay of the coagulant protein from Moringa oleifera seed. WaterResearch, New York, v.39, n.11, p.2.338-2.344, 2005.

HEREDIA, J.B.; MARTÍN, J.S. Removal of sodium lauryl sulphate by coagulation/floculation with Moringa oleifera seed extract. Journal of Hazardous Materials, Amsterdam, v.164, n.2-3, p.713719, 2009.

LEDO, P.G.S.; LIMA, R.F.S.; PAULO, J.B.A.; DUARTE, M.A.C. Estudio comparativo de sulfato de aluminio y semillas de Moringa oleifera para la depuración de aguas con baja turbiedad. Información Tecnológica, La Serena, v.20, n.5, p.3-12, 2009.

LO MONACO, P.A.V.; MATOS, A.T.; EUSTÁQUIO JÚNIOR, V.; NASCIMENTO, F.S.; PAIVA, E.C.R. Ação coagulante do extrato de sementes de moringa preparado em diferentes substâncias químicas. Engenharia na Agricultura, Viçosa-MG, v.20, n.05, p.453-459, 2012.

LO MONACO, P.A.V.; MATOS, A.T.; RIBEIRO, I.C.A.; NASCIMENTO, F.S.; SARMENTO, A.P. Utilização de extrato de sementes de moringa como agente coagulante no tratamento de água para abastecimento e águas residuárias. Ambi-água, Taubaté, v.5, n.3, p.222-231, 2010.

MATOS, A.T.; CABANELLAS, C.F.G.; CECON, P.R.; BRASIL, M.S.; MUDADO, C.S. Efeito da concentração de coagulantes e do $\mathrm{pH}$ da solução na turbidez da água, em recirculação, utilizada no 
processamento dos frutos do cafeeiro.Engenharia Agrícola, Jaboticabal, v.27, n.2, p. 544-551, 2007a.

MATOS, A.T.; EUSTÁQUIO JÚNIOR, V.; PEREIRA, P.A.; MATOS, M.P. Tratamento da água para reúso no descascamento/despolpa dos frutos do cafeeiro. Engenharia na Agricultura, Viçosa-MG, v.15, n.2, p.173-178, 2007b.

OKUDA, T.; BAES, A.U.; NISHIJIMA, W.; OKADA, M. Coagulation mechanism of salt solutionextracted active component in moringa oleifera seeds. Water Research, New York, v.35, n.3, p. 830-834, 2001.

OKUDA, T.; BAES, A.U.; NISHIJIMA, W.; OKADA, M. Improvement of extraction method of coagulation active components from moringa oleifera seed. Water Research, New York, v.33, n.15, p.3.373-3.378, 1999.

PRITCHARD, M.; CRAVEN, T.; MKANDAWIRE, T.; EDMONDSON, A.S.; O’NEILL, J. G. A comparison between Moringa oleifera and chemical coagulants in the purification of drinking water-An alternative sustainable solution for developing countries. Physics and Chemistry of the Earth, Amsterdam, v.35, p.798-805, 2010.

SÁNCHEZ-MARTÍN, J.; GHEBREMICHAEL, K.; BELTRÁN-HEREDIA, J. Comparison of single-step and two-step purified coagulants from Moringa oleifera seed for turbidity and DOC removal. Bioresource Technology, Essex, v. 101, p. 6.259-6.261, 2010.

SCHWARZ, D. Water clarification using Moringa oleifera. Eschborn: Gate Information Service, 2000. Disponível em: <http://www.gtz.de/gate/gateid.afp>. Acesso em: 05 fev. 2011.

SILVA, M.E.R.; AQUINO, M.D.; SANTOS, A.B. Pós-tratamento de efluentes provenientes de reatores anaeróbios tratando esgotos sanitários por coagulantes naturais e não naturais. Revista Tecnologia, Fortaleza, v.28, n.2, p.178-190, 2007. 